\title{
Body mass index as a determinant of postoperative morbidity
}

\author{
Selami Gurkan $M D^{1}$, Ozcan Gur MD¹, Demet Ozkaramanli Gur MD³ , Turan Ege $M D^{2}$, \\ Suat Canbaz $\mathrm{MD}^{2}$, Sahin Iscan $\mathrm{MD}^{2}$
}

S Gurkan, O Gur, DO Gur, T Ege, S Canbaz, S Iscan. Body mass index as a determinant of postoperative morbidity. Curr Res Cardiol 2014;1(2):69-72.

BACKGROUND: The impact of obesity on postoperative mortality and morbidity in coronary artery bypass grafting $(\mathrm{CABG})$ operations is a widely studied but poorly defined topic.

OBJECTIVE: To investigate the effect of body mass index (BMI) on inhospital mortality and morbidity after isolated CABG surgery.

METHODS: Prospectively collected data of a series of 1057 consecutive patients who underwent on-pump isolated CABG surgery were retrospectively analyzed. Patients were divided into five groups according to WHO BMI categorization (defined as underweight [BMI $\left.<20 \mathrm{~kg} / \mathrm{m}^{2}\right]$; normal weight [BMI $\geq 20 \mathrm{~kg} / \mathrm{m}^{2}$ to $<25 \mathrm{~kg} / \mathrm{m}^{2}$ ]; overweight [BMI $\geq 25 \mathrm{~kg} / \mathrm{m}^{2}$ to $\left.<30 \mathrm{~kg} / \mathrm{m}^{2}\right]$; obese [BMI $\geq 30 \mathrm{~kg} / \mathrm{m}^{2}$ to $<35 \mathrm{~kg} / \mathrm{m}^{2}$ ]; and morbidly obese [BMI $\left.\geq 35 \mathrm{~kg} / \mathrm{m}^{2}\right]$ ).

RESULTS: Of 1057 patients, 13 patients (1.2\%) were underweight, $298(28.2 \%)$ were normal weight, $462(43.7 \%)$ were overweight, $218(20.6 \%)$ were obese and $66(6.2 \%)$ were morbidly obese. The mean age was significantly lower in underweight patients, who were also more

$\mathrm{O}_{2}$ nce considered to be a high-income country problem, overweight and obesity are now on the rise in low- and middle-income countries, becoming the fifth-leading risk for global deaths (1). Body fat content is roughly defined by body mass index (BMI) as a measure of body fat accumulation, and is known to be a major risk factor for diabetes mellitus (DM), hypertension (HT) and coronary artery disease (2-5).

There are conflicting studies in literature about the impact of obesity on postoperative mortality and morbidity in coronary artery bypass graft (CABG) surgery. Some studies report lower BMI values increase postoperative mortality and morbidity (6-8), while others claim the opposite (9-11).

In the present study, we investigated the effect of increasing BMI on in-hospital mortality and morbidity after isolated CABG surgery.

\section{METHODS}

Prospectively collected data of a series of 1057 consecutive patients who underwent on-pump isolated CABG between January 2007 and December 2011 were retrospectively analyzed. Patients undergoing combined procedures, valve operations, congenital heart surgery, reoperations, beating heart and off-pump procedures were excluded. The study was approved by the local ethics committee and conducted in accordance with the most recent version of the Declaration of Helsinki and local regulations.

BMI was calculated using Quetelet's formula (weight in kilograms divided by the square of the height in meters) (12). Patients were divided into five groups according to WHO BMI categorization (13) (defined as underweight [BMI $\left.<20 \mathrm{~kg} / \mathrm{m}^{2}\right]$; normal weight [BMI $\geq 20 \mathrm{~kg} / \mathrm{m}^{2}$ to $<25 \mathrm{~kg} / \mathrm{m}^{2}$; overweight [BMI $\geq 25 \mathrm{~kg} / \mathrm{m}^{2}$ to $<30 \mathrm{~kg} / \mathrm{m}^{2}$ ]; likely to be male. In contrast, obese and morbidly obese patients were older, and more likely to have comorbidities such as diabetes and hypertension. The incidence of postoperative bronchodilator use $(\mathrm{P}<0.001)$, leg wound infection $(\mathrm{P}=0.038)$, sternal dehiscence $(\mathrm{P}=0.039)$ and development of new-onset atrial fibrillation $(\mathrm{P}<0.001)$ was significantly higher in obese and morbidly obese groups. In contrast, postoperative prolonged ventilation $(\mathrm{P}<0.001)$, need for blood transfusions $(\mathrm{P}<0.001)$ and revision for bleeding $(\mathrm{P}=0.041)$, as well as gastrointestinal complications $(\mathrm{P}<0.001)$, were significantly higher in underweight patients. Multivariate logistic regression analysis showed that female sex, older age and diabetes mellitis, but not BMI, were independent risk factors for early mortality after CABG surgery.

CONCLUSION: No effect of BMI on early postoperative mortality after $\mathrm{CABG}$ surgery could be demonstrated. However, in terms of morbidity, postoperative bleeding and revision for bleeding were increased in underweight patients while sternal dehiscence, wound infections and occurrence of atrial fibrillation were increased in obese and morbidly obese patients.

Key Words: Body mass index; Coronary artery bypass; Mortality; Obesity

obese [BMI $\geq 30 \mathrm{~kg} / \mathrm{m}^{2}$ to $<35 \mathrm{~kg} / \mathrm{m}^{2}$ ]; and morbidly obese [BMI $\left.\left.\geq 35 \mathrm{~kg} / \mathrm{m}^{2}\right]\right)$.

Operative procedures were performed by the same surgical team using the same surgical techniques. All patients underwent $\mathrm{CABG}$ through median sternotomy using standard anesthetic and surgical techniques. Cardiopulmonary bypass was initiated between the ascending aorta and right atrium cannulation after systemic heparinization at a dose of $300 \mathrm{IU} / \mathrm{kg}$ to achieve activated coagulation time $>400 \mathrm{~s}$. Under systemic moderate hypothermia $\left(32^{\circ} \mathrm{C}\right)$, anterograde hyperkalemic cold blood cardioplegia was administered every $15 \mathrm{~min}$ for myocardial protection. Inotropes were used in hemodynamic instability despite fluid administration in the presence of systolic dysfunction. Intra-aortic balloon pump (IABP) was initiated when low cardiac output with systolic blood pressure $<90 \mathrm{mmHg}$, mean arterial pressure $<65 \mathrm{mmHg}$ and mixed venous oxygen saturation $<65 \%$ despite inotropes.

Preoperative patient characteristics (age, female sex, BMI, history of HT, smoking, DM, preoperative left ventricular ejection fraction, preoperative myocardial infarction, chronic obstructive pulmonary disease [COPD], preoperative bronchodilator use and serum creatinine levels) are presented in Table 1. Table 1 also summarizes operative data such as aortic cross clamp time, total bypass time and number of grafts used.

The clinical data on early postoperative outcomes in categories of BMI are shown in Table 2. Operative mortality (within 30 days of operation) was recorded whether it occured in or out of hospital setting. Postoperative pump failure was defined by inotropic requirement or use of IABP. Postoperative bleeding included need for blood transfusion

\footnotetext{
${ }^{1}$ Namık Kemal University Hospital Department of Cardiovascular Surgery, Tekirdağ; ${ }^{2}$ Trakya University Hospital Department of Cardiovascular Surgery, Edirne; ${ }^{3}$ State Hospital Department of Cardiology, Tekrdag, Turkey

Correspondence: Selami Gurkan, Namik Kemal Universitesi Hastanesi, Kalp Damar Cerrahisi Klinigi, 59100, Tekirdag, Turkey.

Telephone 900282 2505249, fax 900282 2620310, e-mail gurkancem@yahoo.com
}

open Access

This open-access article is distributed under the terms of the Creative Commons Attribution Non-Commercial License (CC BY-NC) (http:// creativecommons.org/licenses/by-nc/4.0/), which permits reuse, distribution and reproduction of the article, provided that the original work is properly cited and the reuse is restricted to noncommercial purposes. For commercial reuse, contact support@pulsus.com 
TABLE 1

Preoperative characteristics and operative data of patients according to body mass index (BMI) groups

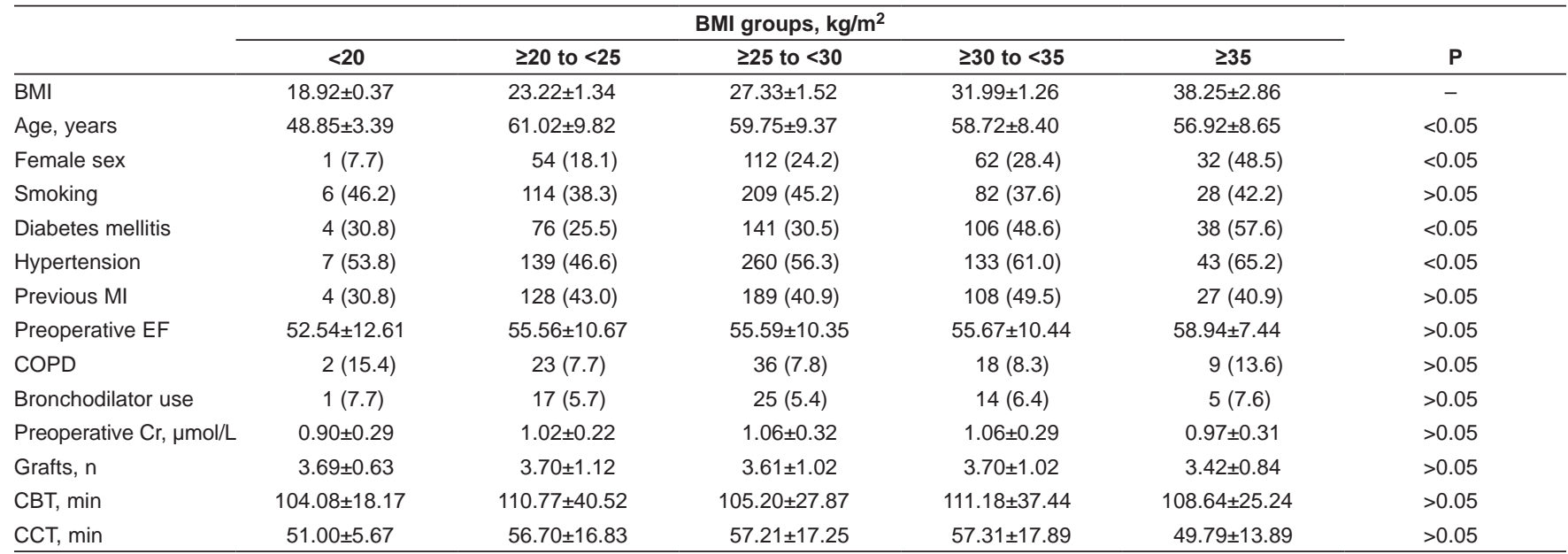

Data presented as mean $\pm S D$ or $n$ (\%) unless otherwise indicated. CBT Cardiopulmonary bypass time; CCT Cross clamp time; COPD Chronic obstructive pulmonary disease; Cr Creatinine; EF Ejection fraction; MI Myocardial infarction

TABLE 2

Postoperative early outcomes of patients according to body mass index (BMI) groups

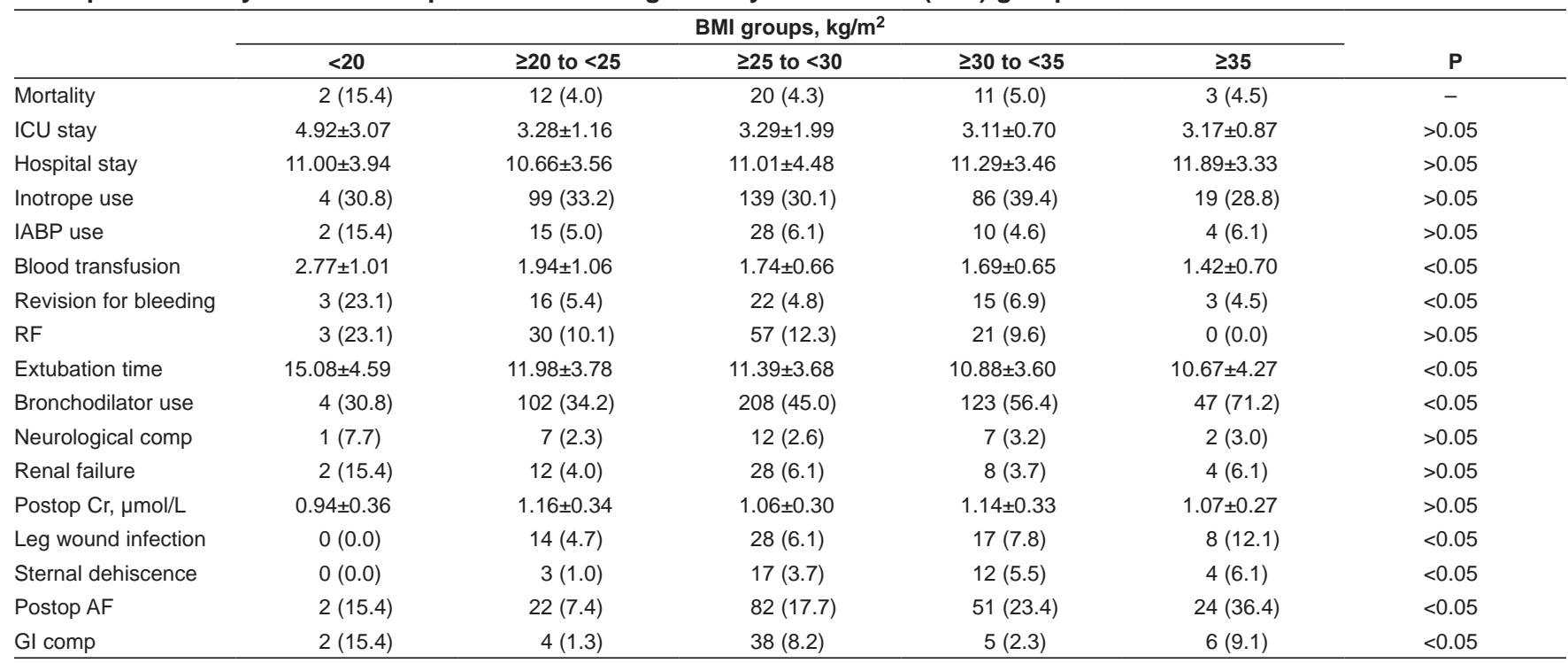

Data presented as mean \pm SD or $n$ (\%) unless otherwise indicated. AF Atrial fibrillation; Comp Complications; Cr Creatinine; GI Gastrointestinal; IABP Intraaortic balloon pump, ICU Intensive care unit; Postop Postoperative; RF Respiratory failure

with hemoglobin $<80 \mathrm{~g} / \mathrm{L}$ and revision for bleeding. Pulmonary complications included respiratory failure (RF) needing prolonged ventilation, prolonged intensive care unit (ICU) stay and need for bronchodilators in the ICU. RF was defined as pulmonary insufficiency requiring intubation and ventilation for a period of $\geq 24 \mathrm{~h}$, at any time during the postoperative stay. Patients who required intubation were counted as having RF when the total ventilation time was $\geq 24$ h. Neurological complications included permanent or transient ischemic episodes. Renal complications included postoperative creatinine ( $>200 \mu \mathrm{mol} / \mathrm{L}$ or doubling increase over preoperative value) and acute renal failure requiring hemodialysis. Infective complications included sternal or leg wound infection, with positive culture requiring antibiotic therapy. Sternal dehiscence (requiring rewiring) and development of postoperative atrial fibrillation (AF) were also recorded. Gastrointestinal complications included upper gastrointestinal bleed presenting with melena or hematemesis, paralytic ileus lasting $\geq 4$ days, acute pancreatitis or ischemic hepatic dysfunction with elevated enzymes.
Statistical analysis

Mean, SD, frequency and percentage values were used in the descriptive statistics of the data. The Kolmogorov-Smirnov test was used to define the distribution of the variables. The analysis of the quantitative variables was performed using ANOVA (and Tukey test in subanalysis) and Kruskal Wallis (and Mann-Whitney $U$ test in subanalysis). The Wilcoxon signed-rank test was used to compare repeated measurements. The analysis of qualitative variables was performed using the $\chi^{2}$ test. Logistic regression test was used to predict the outcomes. SPSS version 20.0 (IBM Corporation, USA) was used for all statistical analyses.

\section{RESULTS}

A total of 1057 consecutive patients (796 men [75.31\%], 261 women [24.69\%]; mean [ \pm SD] age $59.58 \pm 9.34$ years) were included in the present study. Of 1057 patients, $13(1.2 \%)$ were underweight, $298(28.2 \%)$ were normal weight, 462 patints $(43.7 \%)$ were overweight, $218(20.6 \%)$ were obese and $66(6.2 \%)$ were morbidly obese. 
The median BMI was $27 \mathrm{~kg} / \mathrm{m}^{2}$ (interquartile range $24 \mathrm{~kg} / \mathrm{m}^{2}$ to $29 \mathrm{~kg} / \mathrm{m}^{2}$ ) (Figure 1). Table 1 shows the patients' preoperative characteristics according to BMI groups.

The mean age was significantly lower in patients with a BMI $\leq 20 \mathrm{~kg} / \mathrm{m}^{2}(\mathrm{P}<0.001)$ and they were more likely to be male $(\mathrm{P}<0.05)$. In contrast, obese (BMI $\geq 30 \mathrm{~kg} / \mathrm{m}^{2}$ to $<35 \mathrm{~kg} / \mathrm{m}^{2}$ ) and morbidly obese $\left(B M I \geq 35 \mathrm{~kg} / \mathrm{m}^{2}\right)$ patients were older and more likely to have comorbidities such as diabetes and HT $(\mathrm{P}<0.05)$. There was no statistically significant difference in the prevalence of current smoking status ( $\mathrm{P}=0.245)$, COPD $(\mathrm{P}=0.462)$, pre-operative bronchodilator use $(\mathrm{P}=0.947)$, left ventricular ejection fraction $(\mathrm{P}=0.138)$, previous myocardial infarction $(\mathrm{P}=0.238)$, preoperative serum creatinine level $(\mathrm{P}=0.283)$, mean cross-clamp time $(56.54 \pm 17.06 \mathrm{~min})$, mean total bypass time $(108.20 \pm 33.75 \mathrm{~min})$ and mean number of grafts used at CABG (3.6) among BMI groups.

The incidence of postoperative outcomes according to BMI groups are shown in Table 2. No statistically significant association was documented between BMI groups and postoperative occurrence of stroke $(\mathrm{P}=0.809)$, renal failure $(\mathrm{P}=0.243), \mathrm{RF}(\mathrm{P}=0.194)$, postoperative use of inotropes $(\mathrm{P}=0.529)$ or IABP $(\mathrm{P}=0.529)$, ICU $(\mathrm{P}=0.135)$ and hospital stay $(\mathrm{P}=0.141)$, and mortality $(\mathrm{P}=0.422)$. On the other hand, the incidence of postoperative bronchodilator use $(\mathrm{P}<0.001)$, leg wound infection $(\mathrm{P}=0.038)$, sternal dehiscence $(\mathrm{P}=0.039)$ and development of new-onset $A F(P<0.001)$ was significantly higher in obese and morbidly obese groups. In contrast, postoperative prolonged ventilation $(\mathrm{P}<0.001)$, need for blood transfusions $(\mathrm{P}<0.001)$ and revision for bleeding $(\mathrm{P}=0.041)$, as well as gastrointestinal complications $(\mathrm{P}<0.001)$, were significantly higher in underweight patients.

The overall hospital mortality rate was $4.5 \%(n=48)$. The mortality rates among BMI groups were as follows: $15.4 \%$ in underweight patients, $4 \%$ in normal-weight patients; $4.3 \%$ in overweight patients; $5 \%$ in obese patients; and $4.5 \%$ in morbidly obese patients. There was no association between BMI groups and hospital mortality rates in univariate analysis.

The mean length of ICU and hospital stay were $3.26 \pm 1.54$ days and $11.02 \pm 3.96$ days, respectively. There was no correlation between ICU or hospital stay and BMI $(P>0.05)$. The distribution of ICU stay according to BMI groups was as follows: $<20 \mathrm{~kg} / \mathrm{m}^{2}, 4.92 \pm 3.07$ days; $\geq 20 \mathrm{~kg} / \mathrm{m}^{2}$ to $<25 \mathrm{~kg} / \mathrm{m}^{2}, 3.28 \pm 1.16$ days; $\geq 25 \mathrm{~kg} / \mathrm{m}^{2}$ to $<30 \mathrm{~kg} / \mathrm{m}^{2}$, $3.29 \pm 1.99$ days; $\geq 30 \mathrm{~kg} / \mathrm{m}^{2}$ to $<35 \mathrm{~kg} / \mathrm{m}^{2}, 3.11 \pm 0.70$ days; and $\geq 35 \mathrm{~kg} / \mathrm{m}^{2}$, $3.17 \pm 0.87$ days. Hospital stay according to BMI groups was as follows: $<20 \mathrm{~kg} / \mathrm{m}^{2}, 11 \pm 3.94$ days; $\geq 20 \mathrm{~kg} / \mathrm{m}^{2}$ to $<25 \mathrm{~kg} / \mathrm{m}^{2}, 10.66 \pm 3.56$ days; $\geq 25 \mathrm{~kg} / \mathrm{m}^{2}$ to $<30 \mathrm{~kg} / \mathrm{m}^{2}, 11.01 \pm 4.48$ days; $\geq 30 \mathrm{~kg} / \mathrm{m}^{2}$ to $<35 \mathrm{~kg} / \mathrm{m}^{2}$, $11.29 \pm 3.46$ days; and $\geq 35 \mathrm{~kg} / \mathrm{m}^{2}, 11.89 \pm 3.33$ days.

Multivariate logistic regression analysis showed that not BMI but female sex, older age and DM were independent risk factors for early mortality after CABG surgery (Table 3 ).

\section{DISCUSSION}

The influence of BMI on morbidity and mortality after CABG operations is widely studied but varying results have been reported. In the present study, we did not demonstrate any influence of BMI on mortality. Multivariate logistic regression analysis revealed only female sex, older age and presence of DM as independent predictors of mortality. Although the mortality rate in underweight patients $(15.4 \%)$ was higher than other groups, this difference did not reach statistical significance, probably due to the small number of patients in this category $(n=13)$.

The Society of Thoracic Surgeons database study of CABG surgeries on $>500,000$ patients had indicated morbid obesity as an independent predictor of operative mortality (14); however, most recent studies claim the opposite, citing underweight patients to be at higher risk in terms of mortality than obese patients $(2,6,8)$. This is referred to as the obesity paradox, and is partly explained by protective effect of lower systemic vascular resistance and higher plasma renin activity in obese patients (15). Engelman et al (6) have documented the mortality rate following CABG surgery in patients with BMI $<20 \mathrm{~kg} / \mathrm{m}^{2}$ as $10 \%$,

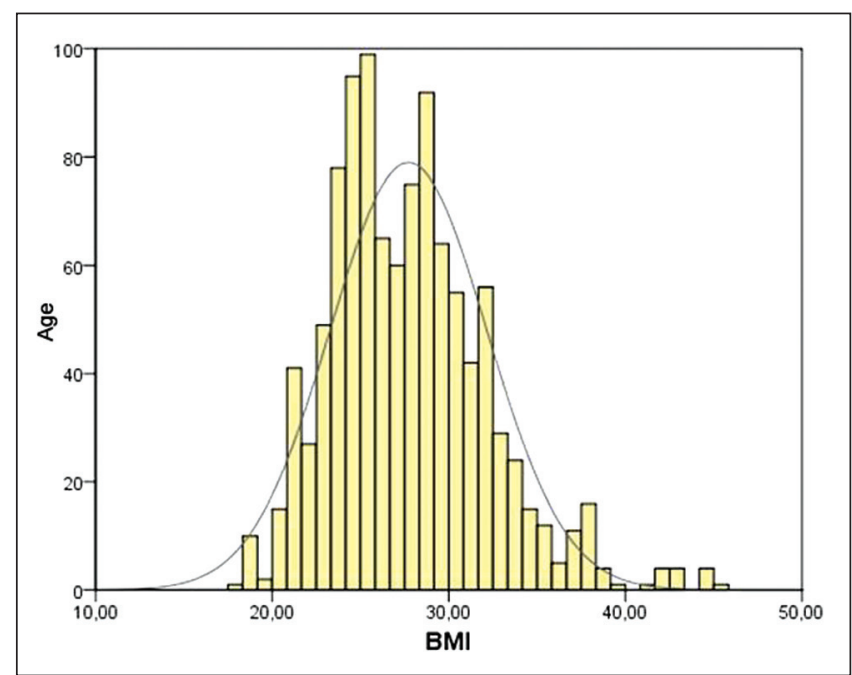

Figure 1) Distribution of body mass index (BMI)

TABLE 3

Multivariate logistic regression analysis for mortality

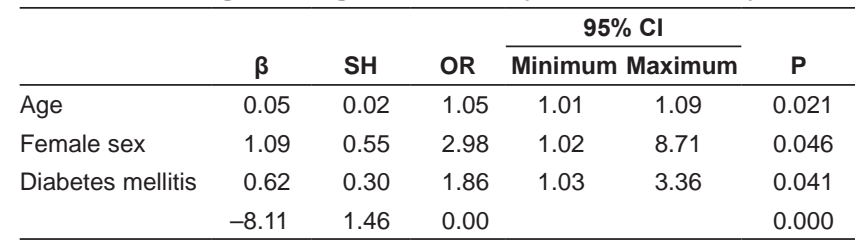

while Reeves et al (2) demonstrated a mortality rate of $6.8 \%$. In our study population, the mortality in underweight patients was $15.4 \%$. Perrotta et al (16) also reported increased morbidity and mortality in patients with low BMIs. Although the incidence of postoperative complications and hospital stay in overweight patients in this study was higher, the early and late mortality was not shown to be increased with increasing BMI. Van Straten et al (17), however, reported in their study involving 10,268 isolated CABG surgery patients that underweight was an independent predictor for early mortality, but morbid obesity was an independent predictor for late mortality.

Similar to other studies, our analysis did not reveal increased early mortality in obese and morbidly obese patients $(8,18-20)$. One possible explanation may be more detailed preoperative analysis and postoperative care in this group of patients.

As reported in the literature, in our study population, obese and morbidly obese patients were more likely to be diabetic and hypertensive. Consequently, similar to most studies, we also revealed an association between obesity and postoperative complications such as leg wound infection, sternal dehiscence, postoperative bronchodilator use and occurrence of AF in patients who undergo CABG $(6,8,21,22)$. The known risk factors for sternal dehiscence and leg wound infection are diabetes, bilateral use of internal mammary arteries, long bypass duration, postoperative bleeding, age and presence of COPD. We believe that, in diabetic patients, preoperative weight loss and strict control of blood glucose would have favourable effects on the outcome.

AF occurs in the postoperative period in as many as 30\% of patients (22). We found a higher incidence of new-onset AF in obese and morbidly obese patients $(23.4 \%$ and $36.4 \%$, respectively). The positive correlation of $\mathrm{AF}$ with obesity is attributed to distended left atrium due to increased plasma volume, variable autonomic tonus and increased neurohormonal activity (23-25).

Some previous studies have also shown an increased morbidity in underweight patients after cardiac surgery. These included revisions for bleeding, transfusions, IABP usage and prolonged ventilator therapy $(2,6,8)$. This increase in morbidity is mainly explained by relatively increased hemodilution due to priming volume, which induces 
development of coagulopathy due to cardiopulmonary bypass, increasing the need of transfusion, RF and prolonged ventilation (26). The results in underweight patients in our study were similar. In contrast, the need for transfusion and revision for bleeding were less in obese patients. This raises the question of whether obesity protects against bleeding. Although the mechanism remains unclear, increased levels of coagulation factors and inhibition of fibrinolytic pathways in obesity presents a possible mechanism. The coexistence of hyperlipidemia with increased platelet aggregation and endothelial dysfunction may also play a role (27-29).

Our study has several limitations. Similar to most studies, we used $\mathrm{BMI}$ as a measure of obesity; however, this is imperfect because BMI is not an adequate reflection of body fat in short people and in older ages with less muscle mass. Another limitation of our study was its

\section{REFERENCES}

1. Poirier P, Giles TD, Bray GA, et al. Obesity and cardiovascular disease: Pathophysiology, evaluation, and effect of weight loss: An update of the 1997 American Heart Association Scientific Statement on Obesity and Heart Disease from the Obesity Committee of the Council on Nutrition, Physical Activity and Metabolism. Circulation 2006;113:898-918.

2. Reeves BC, Ascione R, Chamberlain MH, Angelini GD. Effect of body mass index on early outcomes in patients undergoing coronary artery bypass surgery. J Am Coll Cardiol 2003;42:668-76.

3. Barret-Connor EL. Obesity, arteriosclerosis, and coronary artery disease. Ann Intern Med 1985;103:1010-9.

4. St Jeor ST, Brownell KD, Atkinson RL, et al. Obesity. Workshop III. AHA Prevention Conference III. Behavior change and compliance: Keys to improving cardiovascular health. Circulation 1993;88:1391-6.

5. Hubert HB, Feinleib M, McNamara PM, Castelli WP. Obesity as an independent risk factor for cardiovascular disease: A 26-year follow-up of participants in the Framingham Heart Study. Circulation 1983;67:968-77.

6. Engelman DT, Adams DH, Byrne JG, et al. Impact of body mass index and albumin on morbidity and mortality after cardiac surgery. J Thorac Cardiovasc Surg 1999;118:866-73.

7. Smith RL 2nd, Herbert MA, Dewey TM, et al. Does body mass index affect outcomes for aortic valve replacement surgery for aortic stenosis? Ann Thorac Surg 2012;93:742-7.

8. Potapov EV, Loebe M, Anker S, et al. Impact of body mass index on outcome in patients after coronary artery bypass grafting with or without valve surgery. Eur Heart J 2003;24:1933-41.

9. Habib RH, Zacharias A, Schwann TA, Riordan CJ, Durham CJ, Shah A. Effects of obesity and small body size on operative and longterm outcomes of coronary artery bypass surgery: A propensity-matched analysis. Ann Thorac Surg 2005;79:1976-86.

10. Rahmanian PB, Adams DH, Castillo JG, Chickwe J, Bodian CA, Filsoufi F. Impact of body mass index on early outcome and late survival in patients undergoing coronary bypass grafting or valve surgery both. Am J Cardiol 2007;100:1702-8.

11. Yap CH, Mohajeri M, Yii M. Obesity and early complications after cardiac surgery. Med J Aust 2007;186:350-4.

12. Eknoyan G. Adolphe Quetelet (1796-1874) - the average man and indices of obesity. Nephrol Dial Transplant 2008;23:47-51.

13. WHO Expert Committee. Physical status: The use and interpretation of antropometry. World Health Organ Tech Rep Ser 1995;854:1-452.

14. Prabhakar G, Haan CK, Peterson ED, Coombs LP, Cruzzavala JL, Murray GF. The risks of moderate and extreme obesity for coronary artery bypass grafting outcomes: A study from the Society of Thoracic Surgeons' database. Ann Thorac Surg 2002;74:1125-30.

15. Lavie CJ, Milani RV, Ventura HO. Obesity and cardiovascular disease: Risk factor, paradox, and impact of weight loss. J Am Coll Cardiol 2009;53:1925-32. retrospective design and nonhomogenous distribution of BMI among the groups. The small number of patients in the underweight population was a limitation for the statistical analysis.

\section{CONCLUSION}

Although the early mortality in underweight patients after CABG operation was relatively higher in our study, this did not translate into a statistically significant difference, and we could not demonstrate any effect of BMI on early postoperative mortality after CABG surgery. In terms of morbidity, on the other hand, postoperative bleeding and revision for bleeding were increased in the underweight patients, while sternal dehiscence, wound infections and occurrence of AF were increased in the obese and morbidly obese patients.

16. Perrotta S, Nilsson F, Brandrup-Wogsen G, Jeppsson A. Body mass index and outcome after coronary artery bypass surgery. J Cardiovasc Surg 2007;48:239-45.

17. van Straten AH, Bramer S, Soliman Hamad MA, et al. Effect of body mass index on early and late mortality after coronary artery bypass grafting. Ann Thorac Surg 2010;89:30-7.

18. Gruberg L, Mercado N, Milo S, et al. Impact of body mass index on the outcome of patients with multivessel disease randomized to either coronary artery bypass grafting or stenting in the ARTS trial: The obesity paradox II? Am J Cardiol 2005;95:439-44.

19. Oreopulos A, Padwal R, Norris CM, Mullen JC, Pretorius V, Kalantar-Zadeh K. Effect of obesity on short-and long-term mortality postcoronary revascularization: A meta-analysis. Obesity 2008;16:442-50.

20. Jin R, Grunkemeier GL, Furnary AP, Handy JR. Is obesity a risk factor for mortality in coronary artery bypass surgery? Circulation 2005; 111:3359-65.

21. Wigfield CH, Lindsey JD, Munoz A, Chopra PS, Edwards NM, Love RB. Is extreme obesity a risk factor for cardiac surgery? An analysis of patients with a BMI $>$ or $=40$. Eur J Cardiothorac Surg 2006;29:434-40.

22. Zacharis A, Schwann TA, Riordan CJ, Durham SJ, Shah AS, Habib RH. Obesity and risk of new-onset atrial fibrillation after cardiac surgery. Circulation 2005;112:3247-3255.

23. Pelat M, Verwaerde P, Merial C, et al. Impaired atrial M(2)cholinoceptor function in obesity-related hypertension. Hypertension 1999;34:1066-72.

24. Iacobellis G, Ribaudo MC, Leto G, et al. Influence of excess fat on cardiac morphology and function: Study in uncomplicated obesity. Obes Res 2002;10:767-73.

25. Engeli S, Sharma AM. The renin-angiotensin system and natriuretic peptides in obesity-associated hypertension. J Mol Med 2001;79:21-9.

26. Yellin A, Rafaely Y, Paley M, Simansky D. Major bleeding complicating deep sternal infection after cardiac surgery. J Thorac Cardiovasc Surg 2003;125:554-8.

27. Birkmeyer NJ, Charlesworth DC, Hernandez F, et al. Obesity and risk of adverse outcomes associated with coronary artery bypass surgery. Northern New England Cardiovascular Disease Study Group. Circulation 1998;97:1689-94.

28. Kim J, Hammar N, Jakobsson K, Luepker RV, McGovern PG, Ivert T. Obesity and the risk of early and late mortality after coronary artery bypass graft surgery. Am Heart J 2003;146:555-60.

29. Jarvinen O, Julkunen J, Tarkka MR. Impact of obesity on outcome and changes in quality of life after coronary artery bypass grafting. World J Surg 2007;31:318-25. 